\title{
METHOXYFLURANE IN OBSTETRICAL ANAESTHESIA AND ANALGESIA*
}

\author{
A. Romagnoli, M.D., ANd D. Korman, M.D.广
}

Immediately after the studies conducted by Van Poznak and Artusio in $1960^{1}$ many clinical studies of methoxyflurane appeared in the medical press. ${ }^{2-6}$ The tone of the reports varied from very favourable to dubious. In spite of the uncertainty of these early reports, we decided to investigate the role of methoxy- flurane in obstetrics.

The case room in our hospital is equipped with McKesson anaesthetic machines and Cyprane inhalers, both of the demand-flow type. Our first step was to establish the minute volume in the second stage of labour. After testing many patients, we concluded that the majority exchange $14 \mathrm{~L} . / \mathrm{min}$. with some going up to $20-24 \mathrm{~L} . / \mathrm{min}$. and down to $8-10 \mathrm{~L} . / \mathrm{min}$. Then we sought to determine the concentrations of methoxyflurane delivered by the two apparatuses under different circumstances and at various settings. Figure 1 shows the results we

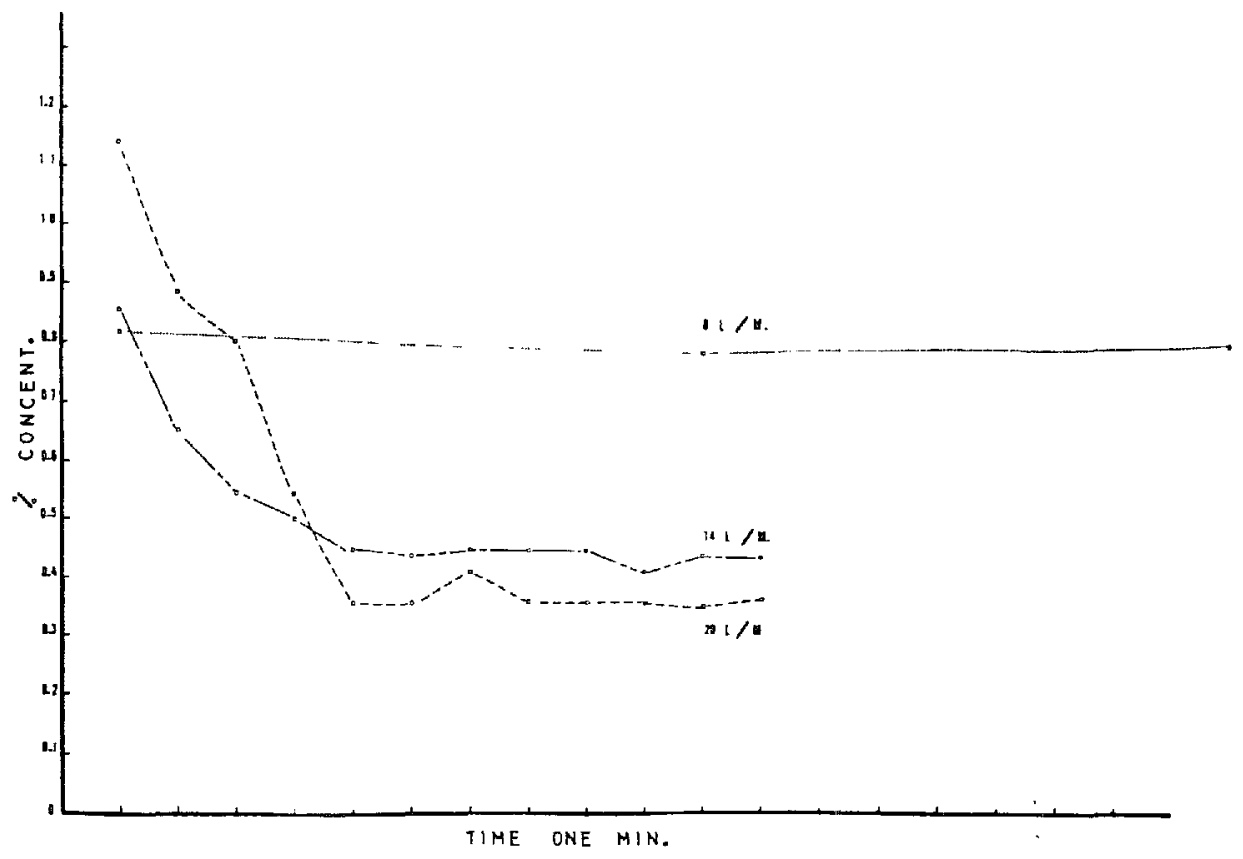

Figere 1. Cyprane inhaler, full on.

obtained from the Cyprane inhaler at three different flows, which correspond to the maximum, minimum, and average minute volume as we found them. When the minute volume is 8 litres per minute the concentration remains steady at 0.8 per cent; when the minute volume is at its maximum of 20 litres per minute,

*Supplied as Penthrane by Abbott Laboratories Ltd., Montreal.

†Department of Anaesthesia, Jewish General Hospital, Montreal.

Can. Anaes. Sor. J., vol. 9, no. 5, September, 1962 
the concentration is initially at 1.15 per cent and decreases rapidly to 0.35 per cent because of the cooling effect, where it remains thereafter; and finally, with the minute volume at 14 litres per minute we found the initial concentration to be 0.85 per cent, levelling off quickly at 0.42 per cent. These concentrations did not seem to be affected by the position of the inhaler in the hands of the patient or nurse. Even at the highest flow, the amount of anaesthetic inhaled is adequate to produce a haze of consciousness and analgesia, while at the lowest flow, in view of the lower cooling effect, the concentration is much higher but the total quantity of anaesthetic inhaled is less, therefore achieving the same result. The setting was full on at all times; anything less resulted in inadequacy. It was noted that the analgesic effect lingered between pains, which is in keeping with the slow induction and slow recovery generally noted so far with this agent.

The vaporizer model 965 of the McKesson machine was also tested for delivered concentration. The flow of gases was maintained at $5 \mathrm{~mm}$. Hg pressure throughout for ease of standardization. Figure 2 shows that at constant temperature, the

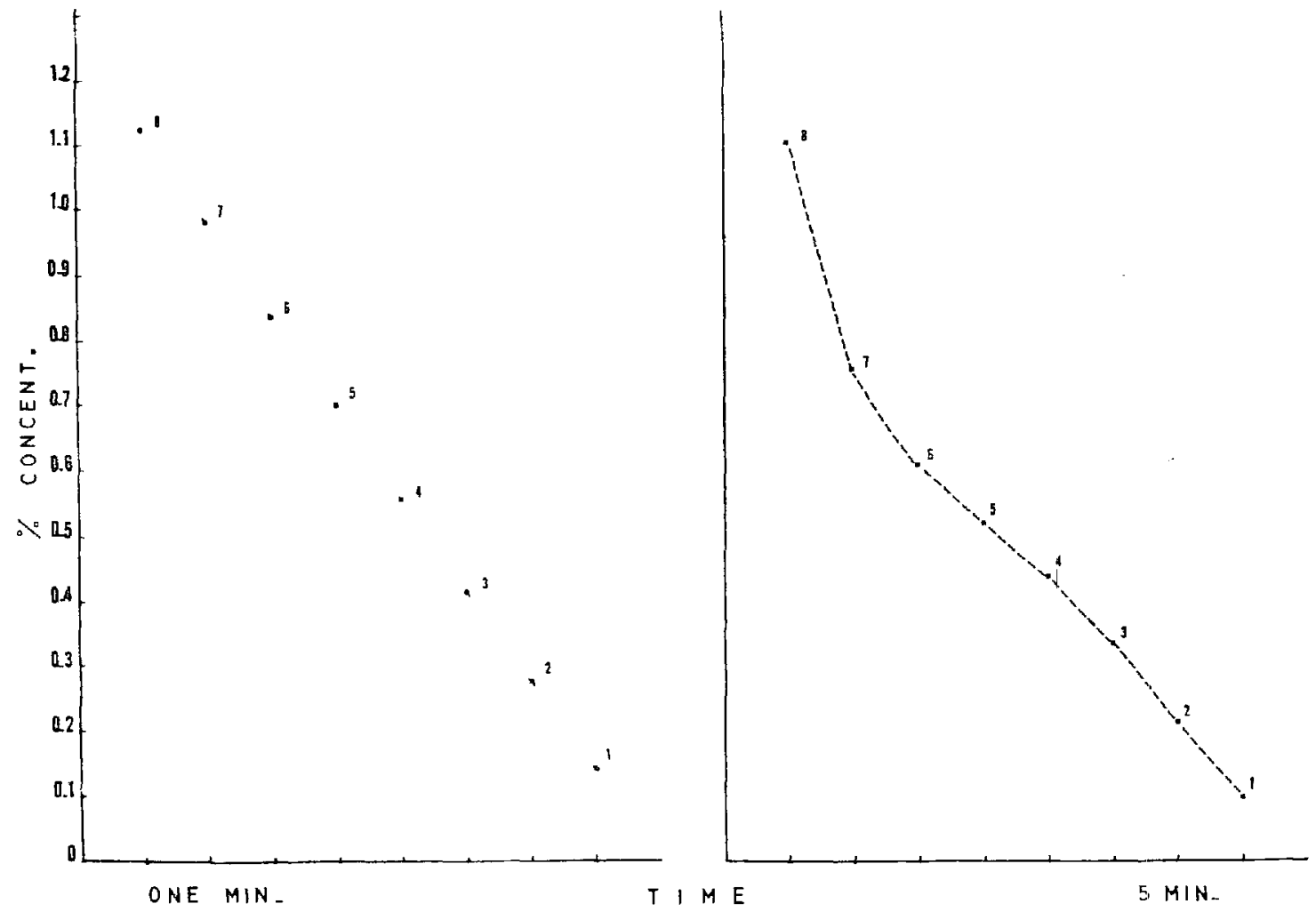

Figlre 2. Mckesson ether jar H-1597, flow 5 mm. Hg pressure, vaporizer model 965

different settings, one to eight, give concentrations varying from 0.13 to 1.12 per cent when the readings were taken at one-minute intervals. If, instead, the readings were taken at five-minute intervals, the concentrations varied from 0.1 to 1.1 per cent, proving the constancy of the results. When the temperature was allowed to vary (Fig. 3) the results were still comparable though slightly lower, showing that the apparatus has inadequate temperature compensation. 


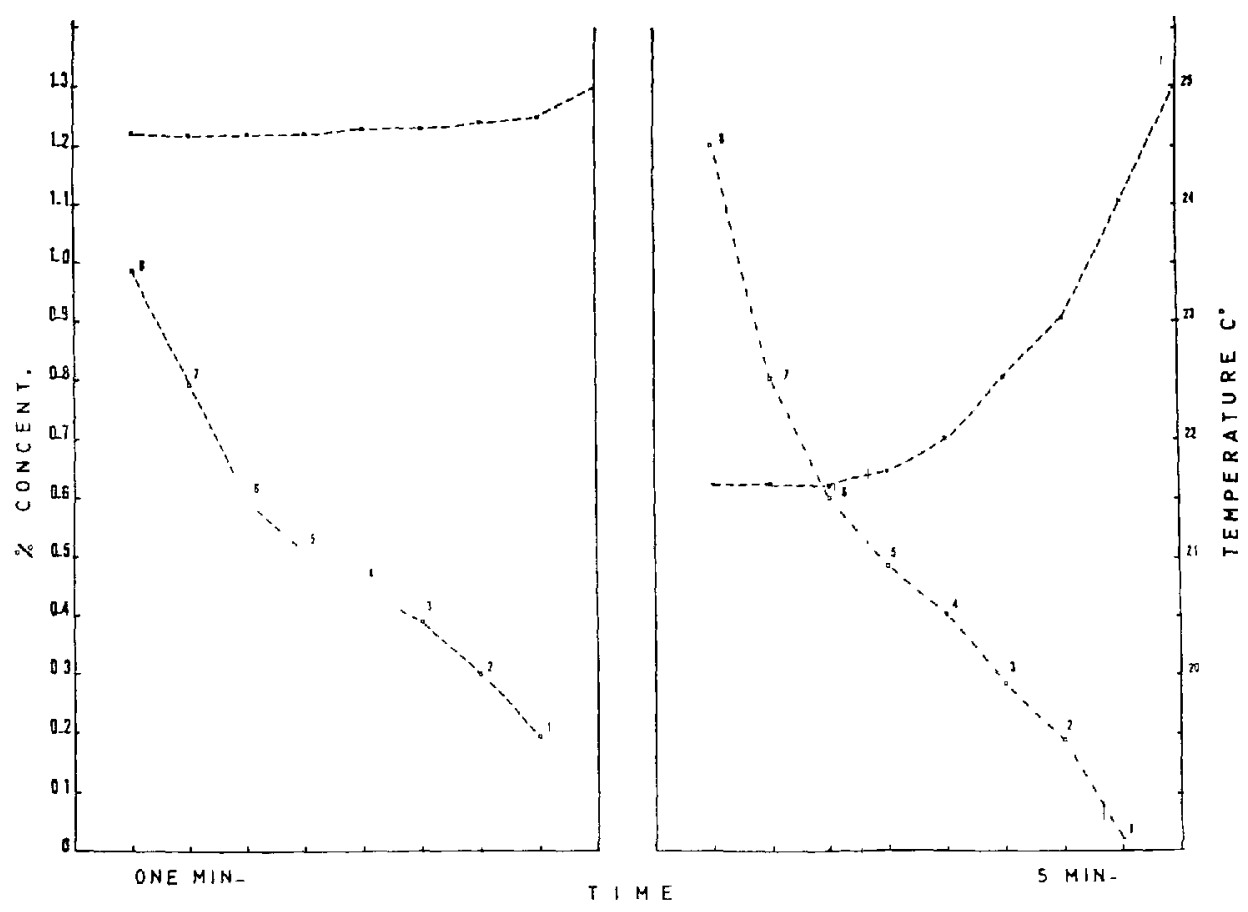

FigURE 3. McKesson ether jar H-1597, flow $5 \mathrm{~mm}$. Hg pressure, vaporizer model 965.

During the administration of the anaesthetic, we found that the patient could be induced and ready for the application of forceps in three minutes provided the concentration was kept at 1 per cent for that period of time. The patient was then in a light stage of anaesthesia but the analgesia was adequate. After the delivery of the head, the concentration could then be lowered ${ }^{2}$ to approximately 0.4 per cent by moving the setting on the vaporizer from number 8 to number 4 . The anaesthetic could be totally discontinued at the beginning of suturing of the episiotomy, and the patient could be awake within two to four minutes. Nitrous oxide and oxygen, 65 and 35 per cent respectively, were used to vaporize the methoxyflurane. In this manner, we have administered 345 anaesthetics for 212 normal deliveries, 16 mid-forceps, 87 low forceps, 14 breech presentations, 5 twin deliveries, and 11 manual removals of retained placentas (Table I). The average duration was 26 minutes and 10 seconds. We supervised the administration of

TABLE I

Cases Done with Methoxyflurane

\begin{tabular}{lr}
\hline Normal deliveries & 212 \\
Mid-forceps & 16 \\
Low forceps & 87 \\
Twin deliveries & 5 \\
Breech deliveries & 14 \\
Man. rem. placenta & 11 \\
Total anaesthesia & 345 \\
Analgesia & 300 \\
Grand total & 645 \\
\hline
\end{tabular}


analgesic concentrations for the first hundred cases, until we felt certain that it could safely be left in the hands of the nursing staff. The average duration was 20 minutes.

The results derived from this series of 645 cases were very consistent and most gratifying. We did not encounter any alteration of cardiac rhythm or blood pressure. The respiration was not depressed, as we often demonstrated by means of the Wright's respirometer. There was no effect on the uterus, no effect on the foetus, no depression of the laryngeal reflexes, no irritation of the airway. There were only eight cases of post-operative vomiting, one of whom was retching before the administration of the anaesthetic. Six babies needed various forms of resuscitation and five were stillborn in different degrees of maceration. Two patients had eclamptic seizures before delivery. We had one case of an unexplained cyanosis of the lips and upper limbs, which developed at the end of the procedure while the patient was still asleep, in spite of good respirations, normal pulse and blood pressure, and the administration of pure oxygen. It persisted for some minutes and disappeared suddenly with no sequelae. Although we do not wish to attempt an explanation of this phenomenon, we would like to point out that this cyanosis disappeared locally on gentle massage, indicating that it was a peripheral vascular effect.

The patients never objected to the odour and had a pleasant memory of the anaesthetic sequence.

Once more we wish to point out that our concentration for anaesthesia never exceeded 1 per cent and even this never lasted longer than four or five minutes, while the maintenance varied from 0.4 to 0.6 per cent. The analgesic concentration, on the other hand, was maintained at 0.42 per cent. Although these levels are far below those recommended by other authors, they produced the good results that are expected of modern anaesthesia. We venture to suggest that the reason why we were able to achieve these results with so much safety for the patient and comfort for the operator at such low concentrations of methoxyflurane may possibly lie in the fact that the obstetrical patient is suffering from "physiological pain." The mother-to-be reaches the delivery room after approximately nine months of emotional, psychological, and biological preparation. This experience is most anxiously awaited and a great joy is derived from it, because it is the fulfilment of life. These patients are usually most eager to co-operate in every possible way. On the other hand, a patient who undergoes a surgical procedure, though he may approve and accept it as a means to an end, often fears it and rebels against it organically and subconsciously. The muscles are taut, the emotions are tense, fear is at its deepest; this is "pathological pain," the real pain, which requires deeper anaesthesia and greater concentrations of agents.

It is practically impossible to achieve overdosage by this method, although it is somehow a different technique. The anaesthetist must learn to master the peculiar physical and pharmacological characteristics of methoxyflurane. It is our opinion that lack of this knowledge may be the cause of some failures and misjudgments in respect to this drug. The obstetrical staff of our hospital has regarded methoxyflurane anaesthesia favourably. The obstetricians as well as the nursing staff felt that labour was never arrested or even delayed, although on some occasions it 
was noticed that some patients rather enjoyed the detaahed state that the vapour would cause.

To conclude, our 645 cases in which this method was used proved to us that methoxyflurane is a safe anaesthetic and analgesic agent in obstetrics, because of the low concentrations that can be administered. It is conceivable that anaesthetic drugs that are now considered unsuitable in obstetrics may be better accepted if a technique is found that lends itself to the different requirements.

\section{SUMMARY}

Methoxyflurane was used to produce anaesthesia and analgesia for 645 obstetrical cases. The low concentrations used afforded good results and absence of side-effects. The method and the results are discussed.

\section{RÉSUMÉ}

Les auteurs ont utilisé le méthoxyflurane pour produire l'analgésie et l'anesthésie obstétricales chez 645 malades.

Ils ont établi que la majorité des malades, au deuxième stage du travail, conservent un volume/minute respiratoire d'environ $1 \neq$ litres avec un minimum de 8 à 10 litres et un maximum de 20 à 24 litres. Ils ont alors déterminé les concentrations de méthoxyflurane fournies par l'inhaleur Cyprane et le débit à donner avec l'appareil à anesthésie McKesson pour donner une atmosphère équivalente au volume/minute respiratoire. Au début, le méthoxyflurane ne dépassait pas des concentrations de 1 pour cent. Une concentration de 1 pour cent procure une anesthésie adéquate en trois minutes pour appliquer un forceps et, après l'accouchement de la tête, la concentration peut être diminuée à 0.4 pour cent. Pour vaporiser le méthoxyflurane, on a employé un mélange de protoxyde et d'oxygène dans la proportion de $65: 35$.

Chez aucun de ces cas, les auteurs ont observé des modifications du rythme cardiaque, de la tension artérielle ou de la respiration. On n'a noté aucun effet appréciable sur l'utérus ou sur le foetus. Cet agent s'est avéré acceptable pour les malades.

\section{REFERENCES}

1. Van Poznak, A. \& Artusio, J. R., JR. Anesthetic Properties of a Series of Fluorinated Compounds. I. Fluorinated Hydrocarbons. Toxicol. \& Applied Pharmacol. 2: 363 (1960).

2. Van Poznak, A. \& Antusio, J. R., JR. Anesthetic Properties of a Series of Fluorinated Compounds. II. Fluorinated Ethers. Toxicol. \& Applied Pharmacol. 2: 374 (1960).

3. Artusio, J. F., JR., et al. A Clinical Evaluation of Methoxyffurane in Man. Anesthesiology 21: $512(1960)$.

4. Hudon, F. Methoxyflurane. Canad. Anaesth. Soc. J, 8: 544 (1961).

5. Power, D. J. MCGill University Experiences with Methoxyflurane Canad. Anaesth. Soc. J. $8: 488(1961)$.

6. KoK, D. U.S.; DeVilliers, L. S.; Cilluers, A. J.; Oosthuizex, O. A.; Krlger, P.; \& Dreyer, T. N. Methoxyflurane (Penthrane): A New Inhalation Anaesthetic. Med. Proc. (South Africa) 8: 9 (1962). 